\title{
IoT Technology for Facilities Management: Understanding End user Perception of the Smart Toilet
}

\author{
Venushini Raendran ${ }^{1}$, R. Kanesaraj Ramasamy ${ }^{2}$ \\ Faculty of Computing and Informatics \\ Multimedia University \\ Cyberjaya, Malaysia
}

\author{
Intan Soraya Rosdi ${ }^{3}$, Ruzanna Ab Razak ${ }^{4}$ \\ Nurazlin Mohd Fauzi ${ }^{5}$ \\ Faculty of Management, Multimedia University \\ Cyberjaya, Malaysia
}

\begin{abstract}
The Internet of Things (IoT) plays an important role as an emerging technology. IoT platforms enable electronic devices to collect, process, and monitor various types of data. The Smart Toilet system featured in this paper is based on IoT technology, and it is designed for resource optimization in facility management services and for bringing convenience to individual end users. This paper presents a study conducted on individual end user perception of the Smart Toilet. A total of 124 respondents had participated in the study's online survey and statistical data analysis methods were used to analyse the data. Results indicate user perception of the proposed Smart Toilet and the Smart Toilet app.
\end{abstract}

Keywords-IoT system; facilities management; smart toilet; resource optimization; user acceptance; theory of planned behaviour

\section{INTRODUCTION}

Information and communication technology (ICT) has been dominating the world in all aspects with the foundation of rapid internet technology growth in the last few decades. The increased growth in cities and dependencies on ICT and efficient management of critical infrastructure address the challenges of development and sustainability of technology [1]. For the last few years, the development of technology and research on ICT have been devoted to the Internet of Things (IoT) [2]. IoT platforms offer provisions for most electronic devices to collect, process, and monitor various types of data. Evolution of IoT in the smart cities, smart homes, wearable technologies etc. enables us to monitor real-time data from electronic devices and use the data for critical operations such as rescue missions during emergencies [3]. Its popularity is powered by the fact that many smart city solutions promise to alleviate the real pains of people living in cities. IoT technology is generally used to save energy and resources.

With the current technology of IoT in buildings and residential areas, the environment can be monitored in real time. Retrieving real-time data for rescue operations may well result in survivors during disasters and emergencies [3]. IoT may also be used to enhance security surveillance and improve the deployment of wireless communication. According to [4], with urbanization breaking the $50 \%$ barrier, it is of importance to understand the need for increased efficiency in city management. The author also highlights that highly developed sensing technology allows the gathering and evaluation of real-time data, which is then converted into useful information. However, disadvantages of the technology include precision demands, cost, and intrusiveness and privacy infringement risks. Deploying additional devices would increase the accuracy but at the same time it will increase intrusiveness as well as the cost.

This paper features the proposed Smart Toilet system, which is based on IoT technology and is designed to capture real-time data from sensors placed in toilet facilities towards the optimization of toilet cleaning resources and the sourcing of toilet peripherals. References made to existing studies on toilet management technologies reveal works done such as by [5], who proposes a smart automatic urinal flushing system. Water management system in the form of an automated flushing system is implemented in many public toilets. It helps control the amount of water running in the toilet as well as reduce the chances of cross-infection from toilet users pressing the flush button. However, the drawback of this system is that it is only able to manage the frequency of the cleaning the toilet bowl. Comparatively, a smart toilet system should be a system that manages the entire environment inside the toilet and not just focused on any one toilet part or feature.

Based on the challenges in toilet facility maintenance, the Smart Toilet system architecture is designed to optimize toiletcleaning resources by way of monitoring toilet usage rates using motion sensors, automated janitor scheduling system and predictive maintenance of toilet peripherals through a web dashboard, and providing toilet occupancy data to users in the general public using the Smart Toilet app. However, besides the technology issues, there is a need to understand individual end users' perception of the Smart Toilet. Hence, the research question is: 'How do individual end users perceive the proposed Smart Toilet?' The research objective is to analyze individual end user perception of the proposed Smart Toilet and the Smart Toilet app.

The significance of this paper is its highlighting of the importance of IoT technology, the application of IoT technology in the Smart Toilet System for more effective facilities management, and finally, the perception of targeted end users of the proposed Smart Toilet and the Smart Toilet app. 
This paper is organized such that Section II presents the related works on IoT technology in the context of facilities management and describes the Smart Toilet system architecture. Section III explains the user perception study conducted for the proposed Smart Toilet and covers the discussion of findings and finally Section IV the conclusion of the paper.

\section{RELATED WORKS}

\section{A. IoT for Facility Management}

In the context of this study, the focus on IoT technology is its applications in the facilities management sector as management of toilet facilities falls under this business sector. The field of facility management (FM) is a combination of various disciplines that ensure workplace environment functionality by implementing integration between people, place, process and technology [6]. Facilities management is responsible for the identification, design, specification, procurement and delivery of premises and service requirements that support a company's core business [7]. Facilities management has a strategic nature and it plays a vital role in implementing company policies that are used in strategic costing in service management control [8]. Through facilities management, a company will be able to ensure that the space surrounding their work environment can be enhanced without interfering with the daily movements of the staff and the core business operations of the company [9].

In Malaysia, facilities management standards and regulations are not making as fast a progress as they should, making the country quite left behind in terms of artificial intelligence and IoT technology to manage and integrate facilities management [10]. In 2019, Sirim QAS International Sdn. Bhd, Malaysia's leading certification, inspection and testing body introduced the Facility Management Systems Certification Scheme to pave the way for forward-looking industry players to position themselves for the fourth industrial revolution. Dubbed (ISO) 41001:2018, among its benefits include improved safety, health and productivity of the workforce, better efficiency and effectiveness in facilities management and improved organizational costs [11]. The Smart Toilet system, which will be described in the following section, is a good step in the right direction towards meeting the standards of the ISO certification.

\section{B. The Smart Toilet}

The proposed Smart Toilet system can be implemented in public toilets at common places such as universities, shopping malls, and any other types of low- or high-rise buildings. Its implementation is intended to provide automated janitor scheduling system through a web dashboard, to develop awareness of the importance of clean toilet culture with technology-based tools in line with ISO 17966:2016, and to provide information on toilet occupancy status to the public. By identifying the toilet occupancy status and the location of the nearest toilet in the any given building, end users will able to avoid queuing especially during peak hours. Implementation involves a complete IoT system from sensing capability to data management system with cloud-based Integration. Fig. 1 shows the overall architecture of Smart Toilet implementation.

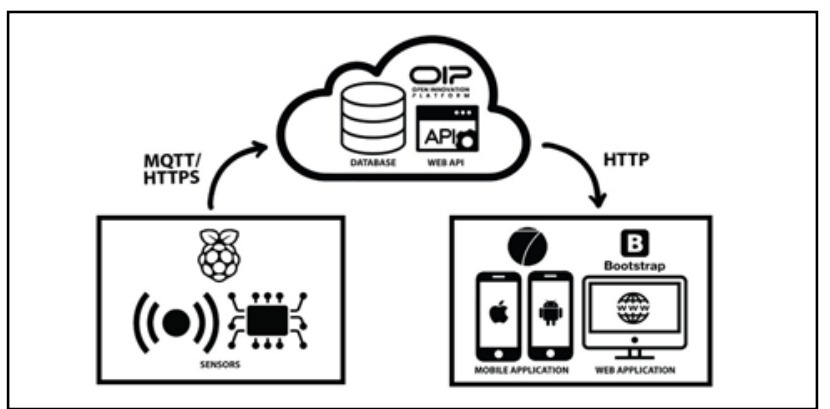

Fig. 1. Overall Architecture of Smart Toilet Implementation.

Raw data collected from the sensors are also known as "real-date-time" which will be stored in the cloud database for further processing. Cloud technology is used not only as a medium to store the data, but it is also required to process the stored data before it is made available to the end user. When data are processed and organized or presented as meaningful information, the data will be extracted to the mobile application via web Application Programming Interface (API) for the end user in a presentable and understandable way. Hybrid type mobile application will be developed. A hybrid application can give freedom for developers to use their web development skills like HTML5, CSS and JavaScript to develop a mobile application. It is cost effective as a single development process handles both Android and IOS application. There are three main phases in this Smart Toilet as shown in Fig. 1 above. Firstly, sensory phase (1), then, cloud management (2) and lastly, mobile development phase for monitoring purposes. (3). Table I shows the description and tools used in the three phases.

Fig. 2 shows the mobile application user interface for the end user and administrative respectively. The Smart Toilet mobile application will help end users to check the occupancy status of toilet cubicles. The green color indicates the toilet cubicles are available while the red color indicates their unavailability. The users would also be able to check on other available toilets in the specific building through the floor directory as shown in Fig. 2. End users can also give feedback in terms of the cleanliness rating of the toilet through mobile application. If the toilet rated less poorly on cleanliness, the janitors on duty will receive notification from their supervisors to clean the respective toilet.

More importantly, the administrative view is as shown in Fig. 3 and 4 respectively, on maintenance prediction and automated janitor scheduling system. There will be three different colors used to ease the readability for the management personnel with green indicating all peripherals are working in good condition. Next, yellow indicates that the peripheral may be due for repairs or servicing within the next three months, and finally, red indicates faulty toilet peripherals.

Fig. 5 shows the activities that have been carried out during the implementation of the Smart Toilet. There are four major phases of activities, namely, 1) Analysis, 2) Modelling, 3) Development and 4) Testing. 
TABLE I. PHASES IN SMART TOILET, THEIR DESCRIPTION AND TOOLS USED

\begin{tabular}{|c|c|}
\hline Phase & Tools \\
\hline $\begin{array}{l}\text { Sensory } \\
\text { phase }\end{array}$ & $\begin{array}{l}\text { In this phase, the sensors are installed in every toilet cubicles } \\
\text { as shown in the figure. This sensor will monitor the real-time } \\
\text { environment. The retrieved data will send to the database to } \\
\text { process in the next stage. The hardware used in this level as } \\
\text { below: } \\
\text { A. Raspberry Pi B+.[12] } \\
\text { It is a credit card-sized computer, which can plug into } \\
\text { any HDMI input device. This device is used as a } \\
\text { microcontroller. The main technical specifications of the } \\
\text { latest model of Raspberry Pi also known as Model B+ } \\
\text { (2018) have the following features: } \\
\text { a) 2.4GHz and 5GHz IEEE } 802.11 . b / g / n / a c \text { wireless } \\
\text { LAN, Bluetooth 4.2, BLE } \\
\text { b) Full-size HDMI } \\
\text { c) } 4 \text { USB 2.0 ports } \\
\text { d) } 5 \text { V/2.5A DC power input } \\
\text { B. Infrared (IR) Sensor } \\
\text { This sensor will be used to detect the obstacles. In ST, } \\
\text { this sensor will be used to for detect the person in the } \\
\text { toilet in and out. Specification of IR sensors are: } \\
\text { a) Input Power: } 3.3 \mathrm{~V} \text { or } 5 \mathrm{VDC} \\
\text { b) } 3 \text { pin interface which is OUT, GND and VCC } \\
\text { c) Two LED indicators, one (Red) as a power indicator, } \\
\text { another (green) as object detection indicator } \\
\text { d) adjustable sensitivity with an onboard potentiometer, } \\
\text { this translate to the adjustable detection range } \\
\text { C. Push-to-On Button } \\
\text { This button is for janitors to indicate the cleaning process } \\
\text { of the toilet is completed after the dirty notification is } \\
\text { alerted. Specification as below: } \\
\text { a) Contact rating: } 125 \mathrm{~V} \text { 3A } \\
\text { b) Thread diameter: } 15.5 m m \\
\text { c) Button diameter: } 13 m m \\
\text { d) Material: Metal (body) and plastic (button) } \\
\text { D. Light-emitting diode (LED) } \\
\text { If the user entered the toilet, this LED is responsible for } \\
\text { alerting other users that the specific toilet is occupied. }\end{array}$ \\
\hline $\begin{array}{l}\text { Cloud } \\
\text { Management } \\
\text { Phase }\end{array}$ & $\begin{array}{l}\text { We used the cloud database to store the data and the system } \\
\text { process as well. All the data will be accumulated from the } \\
\text { sensors will be stored in the cloud database. We use Telekom } \\
\text { Malaysia Research and Development (TMRnD), Open } \\
\text { Innovation Platform (OIP). Besides this server, another } \\
\text { server such as Microsoft Azure or Amazon Web Service } \\
\text { (AWS) IoT server which provides almost the same } \\
\text { functionality for IoT implementation. }\end{array}$ \\
\hline $\begin{array}{l}\text { Mobile } \\
\text { Development } \\
\text { Phase }\end{array}$ & $\begin{array}{l}\text { Mobile development is the last stage of completing Smart } \\
\text { Toilet. In this phase, the mobile application is developed for } \\
\text { end users and administrative respectively where the data } \\
\text { from the cloud database will be revealed with presentable } \\
\text { User Interface (UI). } \\
\text { We used Framework } 7 \text { as our development framework which } \\
\text { supports Model-View-Controller (MVC) architecture. It is a } \\
\text { free and open source mobile HTML framework to develop } \\
\text { hybrid mobile apps or web apps with iOS \& Android native } \\
\text { look. }\end{array}$ \\
\hline
\end{tabular}

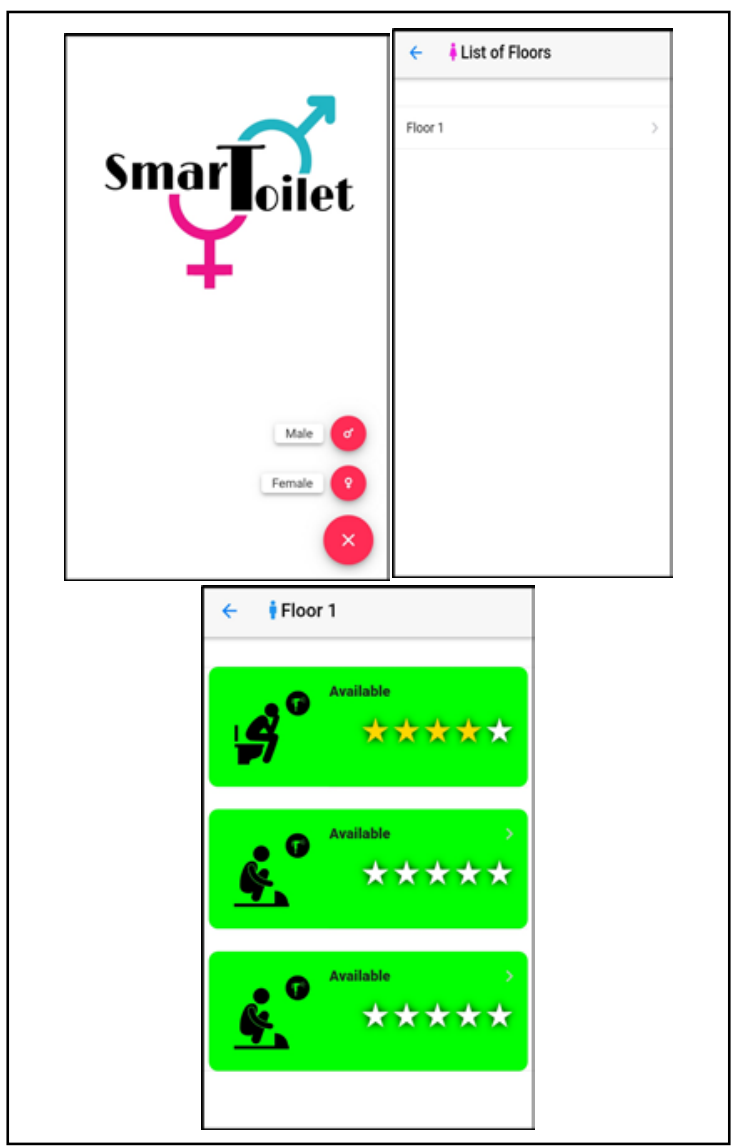

Fig. 2. The Mobile Application user Interface for end user.

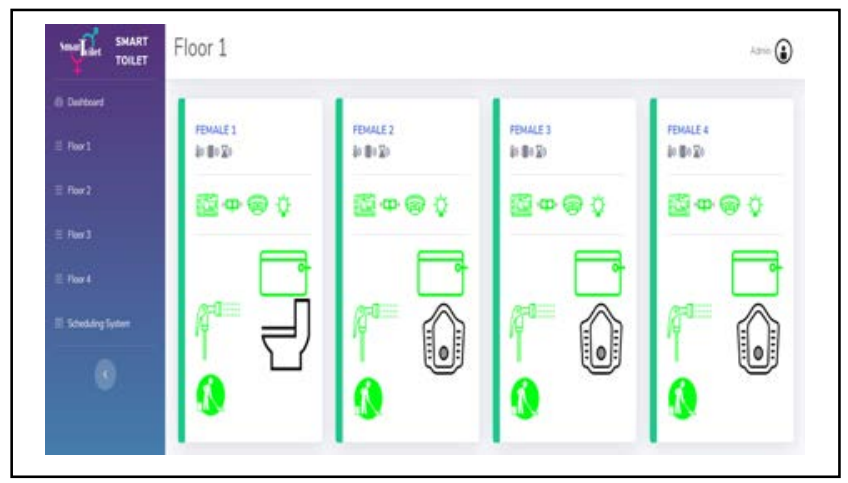

Fig. 3. The web Dashboard view for Administrative on Maintenance Prediction.

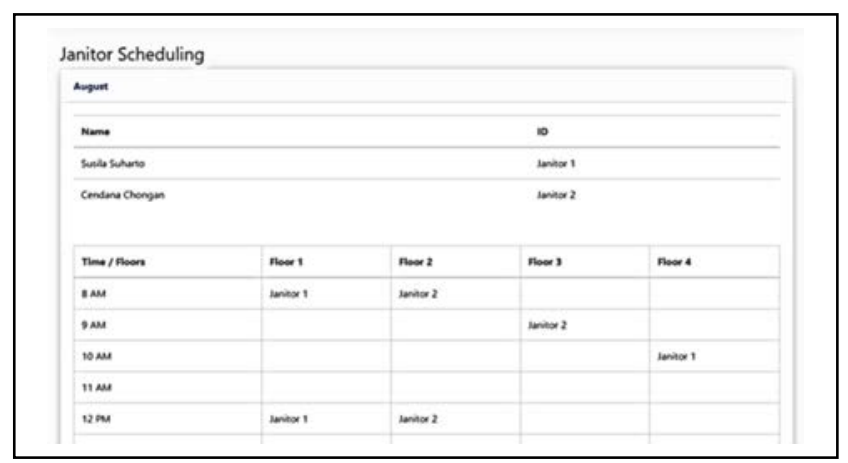

Fig. 4. The Web Dashboard view for Administrative on Janitor Scheduling. 


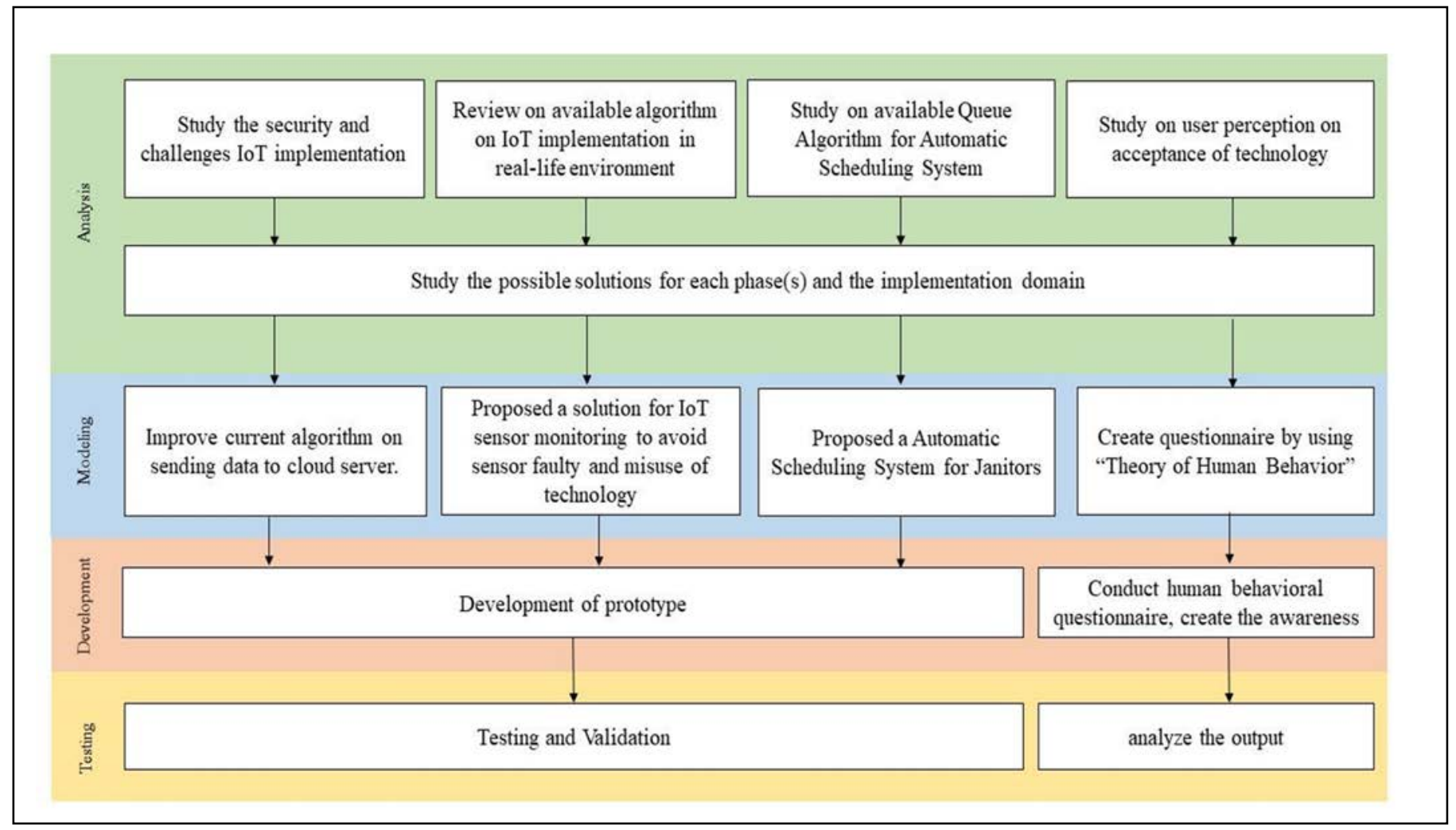

Fig. 5. Activities Carried Out During IoT Implementation.

\section{Analysis}

Review of domain-specific related studies (in this case, toilets) in defining user requirements. At the same time, studies related to algorithms on IoT implementation on the real environment and automated scheduling is considered.

\section{Modelling}

The modelling phase involved designing the hardware and software.

\section{E. Development}

In this phase, we have implemented the prototype by building the miniature toilets.

\section{F. Testing}

In this phase, the miniature Smart Toilet is tested via the performance test and stability test.

\section{USER PERCEPTION StUdies ON THE SMART TOILET}

Researchers in the field of human behaviour define 'perception' as the process that individuals go through in organizing and interpreting information detected by their senses in order to assign meaning to their environmental elements. Informational inputs are then processed into individual decisions and actions. Hence, individual behaviour is based on people's perception of their reality and not necessarily on reality itself [13][14]. To study end-user perception and individual decision making in a systematic manner, reference was made to the theory of planned behaviour (TPB) in the field of social sciences [15].

\section{A. Theory of Planned behavior}

The TPB is an extension of the theory of reasoned action (TRA) developed by [16]. The TPB explains individual perception and decision making by establishing that a person's actual behavior is directly influenced by his or her behavioral intention [17]. In turn, one's behavioral intention is shaped by three antecedents: attitudes, subjective norm, and perceived behavioral control. While a person's attitude refers to his or her favorable or unfavorable assessment of the behavior in question, the subjective norm represents the perceived social pressure to engage in the behavior in question. The third antecedent, which is perceived behavioral control, signals a person's perceived control over his or her ability to perform the behavior. The TPB extends the earlier TRA by adding perceived behavioral control as an additional variable when it was found that there are situations where one may not have complete control over one's behavior. It is established that the level of importance of the three antecedents in predicting behavioral intention changes across different situations and behaviors [16][18].

The TPB has been extensively applied to studies on various issues and across many different disciplines such as health [19], dietetics [20], human resource management [21], entrepreneurship [22], sports science [23], logistics [24], and many more. It has also been applied in studies relating to information technology and smart systems, i.e. Internet of Things (IoT) such as works by [25], [26]. 


\section{B. Research Design, Instrument and Variables}

In developing the Smart Toilet system, information was sought on end-user perception to ensure that the end product catered to the real needs of users, thus resulting in successful user adoption. The study on end-user perception had involved administering a survey questionnaire as the data collection instrument. The survey was conducted online and sent via social networking platforms such as WhatsApp and Facebook. As the product is developed for the Malaysian market, target survey respondents were Malaysians from the general public across different age groups and locations.

Based on the original TPB model, three constructs that determine a person's intention which subsequently influences his or her actual behaviour are attitude, subjective norm, and perceived behavioural control (PBC) [18].

On attitude, many previous studies on technology adoption reported that attitude is an important factor influencing the intention to use particular technology tools, for example, on mobile health technology [27] and on smart home services [28]. Previous studies also found that subjective norm is positively associated with the intention to adopt mobile health service [29], intention to purchase smartphones and intention to use smart home services [30]. Subjective norm is defined as a person's perception of his or her important people's opinion on his or her intention to use [17]. With regards to perceived behavioural control (PBC), past studies support the positive impact of $\mathrm{PBC}$ on the intention to use mobile data services [31], [32]. Following the definition by [28], PBC refers to potential users' perception of the level of easiness to use the technological service.

The work by [28] is used as the main reference for this study as it concerns a similar topic, i.e. end user acceptance of IoT in the context of smart home technology. Another reason is that [28] extended the original TPB model to include five other variables that are relevant predictors in the IoT context, which are: perceived risk, automation, mobility, interoperability, and trust in service providers. Some of the variables studied by [28] are also highlighted in other technology-related studies such as perceived risk in [33] and [34], automation and mobility in [35], and trust in service provider in [36]. However, there has yet to be existing studies found on the concept of interoperability introduced by [28].

As such, furthering the work of [28], the Smart Toilet user perception study had examined public perception on the following nine variables: attitude towards the Smart Toilet app, subjective norm, perceived behavioral control, perceived risk, automation, mobility, interoperability, trust in service provider, and intention to use the Smart Toilet app. In addition, the study also collected feedback on the respondents' frequency in using public toilets, preferred toilet types, and preferred washing amenities. Information from the public survey was to serve as feedback to the technical development team to make adjustments in providing the required necessities to future product end users.

\section{Statistical Data Analysis and Results}

A total of 124 respondents had participated in the survey. Since this initial survey gauges the public's perception towards embedded technology in toilets and their intention to use the Smart Toilet app, the statistical methods are limited to descriptive statistics only.

Participants of the survey consisted of $67.6 \%$ females and $32.4 \%$ males. While participants come from across all the different age groups, i.e. Below 30 years old, between 30-39 years, between $40-49$ years, and 50 years old and above, the majority of them belong to the 30-39 years old category. Fig. 6 presents the breakdown of age groups.

Cumulatively, $73.5 \%$ of the respondents frequently visit public places, and more than half of them frequently use the available public toilets. In terms of respondents' preferred type of toilet and washing amenities, the majority of them chose sitting toilets (55.9\%) as opposed to squatting ones, and they preferred toilets with water hoses (73.5\%) rather than dry toilets or ones with built-in bidets.

The online survey respondents were presented with brief statements relating to their perception of the nine variables, which are: attitude towards the Smart Toilet app, namely subjective norm, perceived behavioral control, perceived risk, automation, mobility, interoperability, trust in service provider, and intention to use the Smart Toilet app. Their responses were measured using a Likert Scale of 1 (Strongly Disagree) to 5 (Strongly Agree). Tables II and III outlines the attributes in the study, the corresponding variables measured, and the descriptive statistics for each variable.

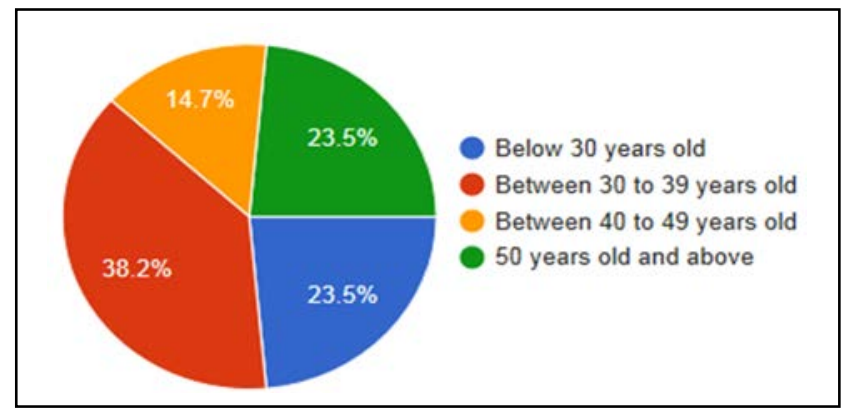

Fig. 6. Percentage of Respondents by Age.

TABLE II. ATtRIBUTES IN THE STUDY

\begin{tabular}{|c|c|}
\hline Item & Statement \\
\hline A & I have positive feelings about using the smart toilet app. \\
\hline B & $\begin{array}{l}\text { People whose opinions are important to me would support my use of } \\
\text { the smart toilet app. }\end{array}$ \\
\hline $\mathrm{C}$ & $\begin{array}{l}\text { I have the resources, knowledge, and ability to use the smart toilet } \\
\text { app. }\end{array}$ \\
\hline $\mathrm{D}$ & $\begin{array}{l}\text { I do not have any privacy concerns from the human motion detection } \\
\text { sensor installed in toilet cubicles to support the smart toilet app. }\end{array}$ \\
\hline $\mathrm{E}$ & $\begin{array}{l}\text { It is convenient that the smart toilet app helps users proactively } \\
\text { without human intervention. }\end{array}$ \\
\hline F & It is convenient to access the smart toilet app anywhere at any time. \\
\hline G & $\begin{array}{l}\text { It is convenient that the smart toilet app can run on existing hardware } \\
\text { (smartphone, tablet, etc.) }\end{array}$ \\
\hline $\mathrm{H}$ & $\begin{array}{l}\text { I think the smart toilet app service provider has customers' best } \\
\text { interests in mind (convenience, user-friendliness, etc.). }\end{array}$ \\
\hline I & $\begin{array}{l}\text { I predict I would use the smart toilet app once it becomes available in } \\
\text { the future. }\end{array}$ \\
\hline
\end{tabular}


TABLE III. DESCRIPTIVE STATISTICS OF EACH VARIABLE

\begin{tabular}{|l|l|l|l|l|l|}
\hline Item & Variable & Mean & Std Dev & Mode & $\begin{array}{l}\text { Cum. \% } \\
\text { for Level } \\
\mathbf{4} \text { \& 5 }\end{array}$ \\
\hline A & Attitude & 4.03 & 0.92 & 5 & $73.5 \%$ \\
\hline B & Subjective norm & 3.79 & 0.96 & 4 & $70.6 \%$ \\
\hline C & $\begin{array}{l}\text { Perceived } \\
\text { Behavioral Control }\end{array}$ & 3.97 & 0.95 & 4 & $73.5 \%$ \\
\hline D & Perceived Risk & 3.94 & 0.66 & 4 & $76.5 \%$ \\
\hline E & Automation & 3.97 & 0.98 & 4 & $73.5 \%$ \\
\hline F & Mobility & 4.15 & 0.87 & 5 & $76.5 \%$ \\
\hline G & Interoperability & 4.12 & 0.82 & 4 & $79.4 \%$ \\
\hline H & Trust & 3.97 & 0.88 & 5 & $67.7 \%$ \\
\hline I & Intention to use & 4.18 & 0.77 & 4 & $85.3 \%$ \\
\hline
\end{tabular}

Table III contains the mean agreement level and its standard deviation, mode and cumulative percentage of respondents who agree and strongly agree to each item statement.

\section{Discussion of Findings}

Based on Table I, the mode for each item indicates the opinion of the majority of respondents (e.g. Level $4=$ Agree; Level 5 = Strongly Agree). The majority of the respondents strongly agreed on the mobility of the app, had positive attitudes towards using the app, and trustful of the app service provider. The mean level of agreement is close to 4 , which suggests that respondents mainly agree with all statements. The last column in the table shows the cumulative percentage of respondents who agreed and strongly agreed with the statements. In brief, the results show that many of the respondents have positive feelings about using the smart toilet app and intend to use it in the future. In addition, the respondents do not have any privacy concerns from the sensor installed in toilet cubicles.

The user perception study presented in this paper is conducted to provide preliminary insights into the market potential of the proposed Smart Toilet and the Smart Toilet app and the public reaction to the idea. Further in-depth empirical investigation of user perception of the technology and how the variables influence user intention in using the app and related services will be included in future research.

\section{CONCLUSION}

This paper describes how IoT technology is used to address challenges in toilet facility maintenance. It describes the Smart Toilet system, which utilizes a complete IoT system from sensory level to data management system with cloudbased integration. The Smart Toilet system allows the collection of real-time data on toilet usage and cleanliness ratings. Big data analytics (BDA) on these data will enable the optimization of resources and predictive maintenance. This paper also answers the question of how individual end users perceive the proposed Smart Toilet and the Smart Toilet app. Findings from the user perception survey shows that respondents have positive feelings about the Smart Toilet and they have the intention to use the Smart Toilet and the Smart
Toilet app in the future. Its implementation in facilities management has the potential to improve the quality of public facilities and services, reduce asset owners' maintenance cost, prolong asset and facilities lifespan, and increase asset value. It can be concluded that the Smart Toilet addresses the needs of the public as well as organizations involved in facilities management.

\section{ACKNOWLEDGMENT}

This work was supported by the Telekom Malaysia Research \& Development grant number [RDTC/180969].

\section{REFERENCES}

[1] A. K. Sikder, A. Acar, H. Aksu, A. S. Uluagac, K. Akkaya, and M. Conti, "IoT-enabled smart lighting systems for smart cities," 2018 IEEE $8^{\text {th }}$ Annual Computing and Communication Workshop and Conference (CCWC), pp. 639-645, January 2018.

[2] E. Theodoridis, G. Mylonas, and I. Chatzigiannakis, "Developing an IoT smart city framework,” IISA 2013, Piraeus, pp. 1-6, July 2013.

[3] K. Akkaya, I. Guvenc, R. Aygun, N. Pala, and A. Kadri, "IoT-based occupancy monitoring techniques for energy-efficient smart buildings," 2015 IEEE Wireless Communications and Networking Conference Workshops (WCNCW), New Orleans, LA, pp. 58-63, March 2015.

[4] J. Jin, J. Gubbi, S. Marusic, and M. Palaniswami, "An information framework for creating a smart city through internet of things," IEEE Internet of Things Journal, vol. 1, no. 2, pp. 112-121, 2014.

[5] K. Osathanunkul, K. Hantarkul, P. Pramokchon, P. Khoenkaw and N. Tantitharanukul, "Design and implementation of an automatic smart urinal flusher,” 2016 International Computer Science and Engineering Conference (ICSEC), Chiang Mai, pp. 1-4, December 2016.

[6] J. Lai, K. Tu, J. Lian, and J. Kim, "Facilities management education in the Four Asian Dragons: a review," Facilities, vol. 37, no. 11/12, pp. 723-742, 2019.

[7] B. Williams, Facilities Economics in the United Kingdom, 2nd ed. International Facilities and Property Information Limited: Kent, 2003.

[8] H. Koleoso, M. Omirin, and F. Adejumo, "Comparison of strategic content of facilities managers functions with other building support practitioners in Lagos, Nigeria,” Property Management, vol. 36, no. 2, pp. 137-155, 2018.

[9] J. M. Wiggins, Facilities Managers Desk Reference. Willey Blackwell Publishers: 2010.

[10] N. Elyna Myeda, and M. Pitt, "Facilities management in Malaysia: Understanding the development and practiced," Facilities, vol. 32, no. 9/10, pp. 490-508, 2014.

[11] The Star, Retrieved from https://www.thestar.com.my/business/ business-news/2019/08/26/setting-the-standards-for-facilitiesmanagement, 26 August 2019.

[12] Raspberry Pi 3 Model B. Retrieved September 3, 2018, from https://www.raspberrypi.org/products/raspberry-pi-3-model-b-plus/

[13] S. P. Robbins, and T. A. Judge, Organizational Behavior, 15th ed. Pearson: London, England, 2013.

[14] J. Wood, R. Zeffane, M. Fromholtz, R. Wiesner, R. Morrison, and P.-S. Seet, Organizational Behavior - Core Concepts and Applications, 3rd ed. Wiley: Australia, 2013.

[15] I. Ajzen, "From intentions to actions: A theory of planned behavior," In J. Kuhl and J. Beckmann (eds), Action Control: From cognition to behavior. Springer: Heidelberg, 1985.

[16] M. Fishbein, and I. Ajzen, Belief, Attitude, Intention and Behavior: An Introduction to Theory and Research. Addision-Wesley: Reading, MA, 1975.

[17] I. Ajzen, "The theory of planned behavior," Organizational Behavior and Human Decision Processes, vol. 50, pp. 179-211, 1991.

[18] I. Ajzen, and M. Fishbein, Understanding Attitudes and Predicting Social Behaviour. Prentice-Hall : Englewood Cliffs, NJ, 1980. 
[19] A. Grønhøj, T. Bech-Larsen, K. Chan, and L. Tsang, "Using theory of planned behavior to predict healthy eating among Danish adolescents," Health Education, vol. 113, no. 1, pp. 4-7, 2013.

[20] A. Silva, I. Figueiredo, T. Hogg, and M. Sottomayor, "Young adults and wine consumption a qualitative application of the theory of planned behavior,” British Food Journal, vol. 116, no. 5, pp. 832-848, 2014.

[21] M. C. H. Ang, T. Ramayah, and H. Amin, "A theory of planned behavior perspective on hiring Malaysians with disabilities," Equality, Diversity and Inclusion, vol. 34, no. 3, pp. 186-200, 2015.

[22] W. J. Aloulou, "Predicting entrepreneurial intentions of final year Saudi university business students by applying the theory of planned behavior,” Journal of Small Business and Enterprise Development, vol. 23, no. 4, pp. 1142-1164, 2016.

[23] C. M. Veraldo, and B. J. Ruihley, "Theory of planned behavior and women in senior-level athletic administration”. Sport, Business and Management, vol. 7, no. 1, pp. 21-37, 2017.

[24] C. Busse, A. Regelmann, H. Chithambaram, and S. M. Wagner, "Managerial perceptions of energy in logistics: An integration of the theory of planned behavior and stakeholder theory,” International Journal of Physical Distribution \& Logistics Management, vol. 47, no. 6, pp. 447-471, 2017.

[25] T. Sommestad, H. Karlzén, and J. Hallberg, "The sufficiency of the theory of planned behavior for explaining information security policy compliance," Information and Computer Security, vol. 23, no. 2, pp. 200-217, 2015.

[26] R. Yadav, V. Chauhan, and G. S. Pathak, "Intention to adopt internet banking in an emerging economy: a perspective of Indian youth," International Journal of Bank Marketing, vol. 33, no. 4, pp. 530-544, 2015.

[27] Z. Hussein, S. W. Oon, and A. Fikry, "Consumer attitude: Does it influencing the intention to use mHealth?” Procedia Computer Science, vol. 105, pp. 340-344, 2015.
[28] H. Yang, H. Lee, and H. Zo, "User acceptance of smart home services: an extension of the theory of planned behavior," Industrial Management \& Data Systems, vol. 117, no. 1, pp. 68-89, 2017.

[29] Y. Sun, N. Wang, X. Guo, and Z. Peng, "Understanding the acceptance of mobile health services: a comparison and integration of alternative models,” Journal of Electronic Commerce Research, vol. 14, no. 2, pp. 183-200, 2013.

[30] H. Chi, H. R. Yeh, and Y. Yang, "Applying theory of reasoned action and technology acceptance model to investigate purchase behavior on smartphone,” Journal of International Management Studies, vol. 6, no. 3, pp. 1-11, 2011.

[31] Z. Deng, X. Mo, and S. Lui, "Comparison of the middle-aged and older users' adoption of mobile health services in China," International Journal of Medical Informatics, vol. 83, no. 3, pp. 210-224, 2014.

[32] M. T. Lu, G. H. Tzeng, H. Cheng, and C. C. Hsu, "Exploring mobile banking services for user behavior in intention adoption: using new hybrid MADM model,” Service Business, vol. 9, no. 3, pp. 541-565, 2014.

[33] M. C. Lee, "Factors influencing the adoption of internet banking: an integration of TAM and TPB with perceived risk and perceived benefit," Electronic Commerce Research and Application, vol. 8, no. 3, pp. 130141, 2009.

[34] J. S. Chou, and I. G. A. N. Yutami, "Smart meter adoption and deployment strategy for residential buildings in Indonesia," Applied Energy, vol. 128, no. 1, pp. 336-349, 2014.

[35] M. E. Porter, and J. E. Heppelman, "How Smart, Connected Products Are Transforming Competition,” Harvard Business Review, 2014. Access date: 24s August 2018. https://hbr.org/2014/11/how-smartconnected-products-are-transforming

[36] M. Noh, and K. Lee, "An analysis of the relationship between quality and user acceptance in smartphone apps," Information System EBusiness Management, vol. 14, pp. 273-291, 2016. 